\title{
Development and Influence of Chinese Copper Shang Culture on Copper Instrument
}

\author{
Zilong Song \\ Qujing Normal University, Qujing, Yunnan, 655011, China
}

\begin{abstract}
Keywords: Bronze culture, Brass musical instruments, Musical bells, Technology, Music art concept
\end{abstract}

\begin{abstract}
In the pre Qin era, metal mining and smelting is an important driving force for national economic development and civilization, prosperity of the copper smelting proposed "bronze culture" also runs through the whole China inland In the early Western Zhou Dynasty, the bronze instrument has become an important product of Zhou Culture in Qin and Han Dynasties, which has been greatly enriched. In this paper the development of brass instruments, technology research and the music art philosophy reflection under the influence of Chinese copper business culture were discussed.
\end{abstract}

\section{Introduction}

In the long history of China, copper is regarded as a very special metal material, which inherit the three generation of bronze civilization. Also the main carrier of the economic of the Qin and Han Dynasties. As one of the Chinese ancestors of the earliest people understanding and mining and smelting of metal, in the philosophy of the pre Qin's culture of copper, copper is gold. So in ancient times, copper was not only a pure metal, but also a symbol of human civilization evolution, with symbolic significance.

\section{Bronze culture and bronze music}

The concept of copper business culture. The origin of copper business culture was very early, according to historical records as early as in the Xia, Shang and Western Zhou Dynasties period, bronze culture has been extremely prosperous. The tripod created by the copper smelting and casting copper together was the highest symbol of national law, namely "Jiuding". In the Qin and Han Dynasties, copper business culture has become a symbol of national wealth, and gradually to the peak. In the Qin and Han people's thoughts, copper business culture is dominated by mining, smelting, casting, transportation, economic and cultural activities and material civilization and spiritual civilization performance, it reflects the people's concept of value and labor skills, with cultural heritage. And the system of market economy and trade, which is decided by "copper merchant", also gives the connotation of "culture". Another is around copper products trading, processing, archiving and other commercial and cultural activities, cultural phenomenon which is generated from the copper smelting also known as copper business culture, including the the production and dissemination of brass instruments.

Bronze culture and brass instruments. In the Three Dynasties period and the pre Qin period, copper business culture was extremely developed, which had been widely extended to various fields, including the field of music and art culture. For example in the Western Zhou Dynasty and the period of Warring States were more important bronze instrument -- bronze bell music was regarded as country music jack was numerous musical instruments for the first time at that time. Western Zhou Dynasty is the copper business culture period, at the same time it is also the origin of the bronze bell stage, it is divided into "new clock" and "bells" in two, so at the time of the bell to play a "two tone effect" skills. It is also in the Western Zhou Dynasty, bronze bell laid the foundation, the ritual system of the Western Zhou Dynasty until the Eastern Zhou Dynasty, which is at the flourishing development period. In the Warring States period and the pre Qin period, it would be a blend of its own and copper business culture to the peak, and even became the people's minds at the time of the music art and culture of the only belief. 
The evolution of the bronze Music Clock Based on the bronze culture. The late Shang Dynasty was a milestone in the origin of Chinese bronze music. Because of the prosperity of the copper business culture, the function of the bronze bell in the process of manufacturing has also been changed. It really transformed from the body in vitro strike music bell bell, also copper bell also appears in marshalling. Thus, brass instrument family joined the new members. It also from the monomer of musical instrument of transformation for similar pieces of marshalling melody rhythm musical instrument, which was due to copper business administration of social economy great prosperity brought about by the music, art and culture to enhance the level, also from the side reveals the people for music artistic needs improvement. The bronze chime music performance for its glory in the period of the Western Zhou Dynasty, spring and autumn and the Warring States of the pre Qin and lay a solid foundation of the improving.

Yong zhong and new zhong in bronze bells. As mentioned above,Yong zhong and the new zhong were the two largest category of bronze bells. In the Western Zhou Dynasty, Yong Zhong showed three sequence phenomenon, and it was produced in the South Tongnao piece in the music etiquette was quite different. The bells of direct and turn, so it can also be suspended strike, which makes it become one of the important instruments to meet national concierge guest, also on behalf of the bronze culture at the time of the clock is so Ningbo be promoted step by step, with royal expensive instruments, this made it an important historical position in bronze culture period.

It was argued that although Yong Zhong in Western Zhou in the form of inherited was north of the small cymbals into the traditional editing and handle on the hanging ring suspended sound playing method. It also drew on the southern Nao milk egg, expand the clock body quality sound effects, and the harassment of decorative texture had become the instrument of its unique decoration, whether from the appearance or the inner temperament excellent Yong Zhong. So people called Zhou Yong Zhong combined copper business culture and civil culture and art exchange crystallization of great musical instruments. It should be said that is highly developed economy to let people learn to innovate, to create such a masterpiece, let brass instruments in Chinese history left a much told story.

Compared to the new clock appeared later, Yong bell, it was representative of the copper business culture in the spring and autumn period. When copper smelter manufacturing to bells based, and Niu bell was on the basis of bells and the original Yong Zhong, combine both in structure and technology advantage to build out new types of musical instruments. Although it is production, but combines the advantages of Ningbo and bell clock. Under the influence of the social factors in the copper business, the social influence of the New York bell has become increasingly prominent. Although it in size was much smaller than the Yong Zhong, known as "small bells", but it made up for the Yong bell temperament problems, making sound of chimes column more complete, in sensual pleasures more pleasant. More important was that it did not violate the Royal guarded the rites and music system, for at that time a number of small and medium-sized financial aristocracy became the first choice, reflecting the was of the nobles in the spring and Autumn Period pursuit sensual music beauty, form beauty and artistic beauty, greatly enhance the essence of its entertainment function, is copper in business culture of the best melodic instruments on behalf of.

Altogether, from multiple perspectives instrumental morphological evolution, social, economic, cultural and political needs, Yong Zhong, Niu bell were in business culture copper brass instruments the best interpretation of, their performance evolution represents the progress of society, economy and culture was in strict political culture under the background of the development, brass instruments to to the evolution of the society produced

\section{The technical study of the bronze bell in the pre Qin bronze culture}

In the pre Qin period, copper was still the essential material for the national strategy. The Middle Kingdom and the national aristocracy more and more in demand for copper materials, both agricultural production, military or military life culture, reflects the importance of copper resource In "Huayang", when the Qin Mieshu, Qin people with the advanced copper Shang culture into Shu, Qin people called "capital Feng Tu, a copper salt." Visible copper business culture has been deeply rooted in the history of the people. For a country, to other countries in the form of combat forces to destroy 
so as to obtain copper resources, is considered to be open source, as the gold cloth law "said" province, officer in July male dung is not versions that have long general extravagant Chi. The gold and copper iron into the thought." Even by the waste copper, will be recycled to be used, the precious visible copper resources. And in the arts, brass instruments still represent was first Qin right noble taste, so under the strict copper administration, bronze process also showed its uncompromising attention to beauty.

The decoration technology of bronze bells in the pre Qin Period. The pre Qin era bronze Music Clock in the device body to flat carving, sculpture and high relief decorative pattern mainly, which was an important part of bronze musical instruments in the artistic structure of, reflecting the deep foundation of third generation period and the pre Qin Dynasty art. In the Western Zhou Dynasty, Shang style was quite heavy, and even affect the trend of the copper of the Shang culture, therefore like Taotie such main features are preserved, and animal mask and Yunlei is as brass instruments of shading, the lines full of change and with the period of three generations of people for animal belief components. For example, the double dragon thunder bird grain pattern so gradually increased. These patterns not only echoes the faith of the people at that time, but also reflects the Shang Dynasty bronze after multiple culture art nouveau style. For example long bird patterns in the pre Qin era were still popular, and double dragon thunder pattern was relatively decoration simple and plain, but the whole people feeling of rough untidy, and geometric feeling strong. As shown in Figure 1

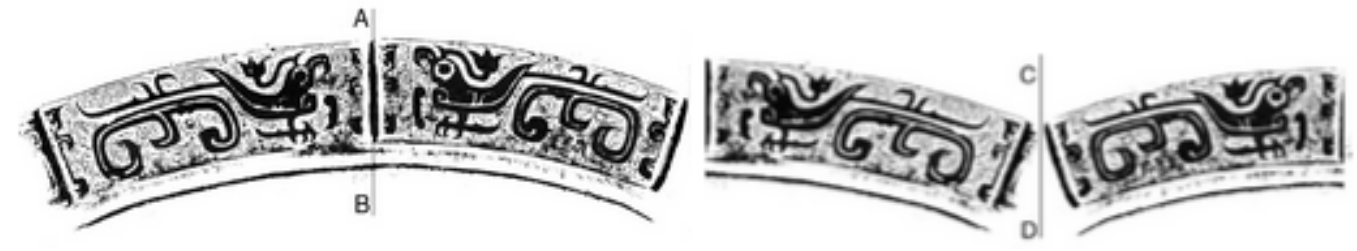

Fig. 1. The long bird decoration on the Western Zhou bronze bell

Regarding to the decoration, the three generation period of mold and carve patterns were engraved on the bronze bell's wall, and only one layer. But in the pre Qin period, instrument die wall was added to the mud belt, and in the glyph also increased the cloudy Lei Wen and gluttonous two layers, some even added the third layer based on relief to outline lines. This continuous practice by printed on the clay mold with longitudinal transverse and dense such as pattern network and even some musical instruments of all devices are printed with patterns, although not the main lines and shading, but the continuous pattern decoration also let users overwhelmed, feel the from in three generations of the pre Qin heavy historical and cultural heritage.

In the pre Qin period of the bronze bells of the decoration technology. After the evolution of the three dynasties casting skills, pre Qin era bronze forging technology has been quite rich, it use prior to the more commonly used casting, just from whole molded fan programming monomer do die, which was more conducive to musical instruments in the complex structure of creative design. In Qin and Han Dynasty, there appeared a needle for the bronze bell. This method requires fine, and was considered to be a great invention of ancient Chinese bronze instrument. Wax casting method had many advantages, and the method was simple, and the overall system was no need to be divided into the whole mold, and the fine degree of musical instruments produced by this method was higher, the surface was smooth, and it was the most advanced bronze forging technology in the world.

In general, whether it was Yong bells or Niu bell, casting technology of the pre Qin period reflects the rigorous and both the aesthetic characteristics, which uphold the period of three generations of heavy organic, shape and pattern elegant and solemn inscription rigorous neat features, and shape and decorative pattern was made also simple, more long inscription, whole line skilled beautiful but does not lose unrestrained temperament. It also with copper Shang culture together into the its development stages of maturity [2]. 


\section{The art characteristics of the bronze bell in the pre Qin Period}

We can say, social values reflected by copper business culture were inclusive, third generation and the pre - Qin period of education value was the best embodiment, so in such a higher quality of social culture, bronze bell music reflects the noble art of quality for more people to accept and study, form based on the concept of copper business culture from the perspective of social and cultural, religious worship and a sense of innovation.

Cultural view. First Qin thought and character was inclusive and longing for peace of, this with their long experience in the war infestation, living environment complex. In the pre Qin period to maintain and carry forward the three generations of the glory of the Central Plains culture and the bronze of Shang culture traditional at the same time, also with other tribes formed a mutual influence and penetration, so now recorded in the history books of the bronze instrument can even revealed some of the northern grassland culture color. For example more plain and decoration of the chimes of Quintana more concise and practical, this was on North rugged simplicity style of culture embody the best. Therefore, we can say in pre Qin period and the historical and cultural traditions of the relative integration of a strong period, brass instruments of cultural elements is diverse, it had elements inherited from the spring and Autumn period, can be seen in the minority in Zhongyuan and northern culture shadow. It was shown that based on great prosperity under the influence of copper business culture and cultural exchanges between different groups has been strengthened, this also let brass instruments has become one of the prevailing social diverse arts and culture of unity.

The value belief. In the pre Qin bronze musical bell unearthed in Shanxi, it can also be seen on the unique musical instruments on the bronze. As Zhang Guangzhi of our country's archaeology scholar, "the combination of politics, religion and art was a common phenomenon in the ancient world. [3] "in Chinese, this phenomenon was reflected in the bronze cultural background of the people most brass instruments advocating ornamentation. For example, in the decoration of birds, animals, flowers, although some of the description of the life, but it can reflect the people's ideas and beliefs, reflecting the people's worship of primitive religion. But central and northern culture of bronze musical instruments on the animal worship was different in Southwest China's spirits worship. This was a kind of nature worship, also prove that the extension of the pre Qin and the third generation of copper Shang culture keen.

Technological innovation. In the pre Qin period of brass instruments with people's creativity of art at that time, like in copper merchants copper policy under the social background, the ritual system abnormal strict norms, to modern people's point of view, and even some stereotyped. But in the understanding and evolution process of musical bronze bells, when people were not conservative, because of musical bronze bells from the original single musical instrument to have four pieces of the chime, 9 Niu bell, and temperament of the full brass instrument combination. It not only embodied the music art in copper Shang culture in the leading position, on the other side analysis of the when human's innovation, can be said in terms of culture and art, ancient people was not conservative and even some avant-garde, rapid development of musical bronze bells of evolution was the evidence. The music deep understanding and their pursuit of art also proved that the society nurtured in the copper business culture prosperity under are not without justification

\section{Summary}

The evolutionary history of brass instruments under the influence of the development process of musical bronze bells, process characteristics and the taste for art analysis of the in Chinese copper business cultural background, in which feelings to the third generation of people in pre Qin period for copper business culture, brass instruments of understanding and belief. It should be said, as China and the world's most popular art and cultural heritage, which was unique in the era of charm and artistic connotation, which is affected by the copper business culture, but also affect the development path of Chinese civilization, and as a national music culture glory, it's value was self-evident, worthy of forever. 


\section{Acknowledgments}

This paper is the subject of Yunnan Qujing Normal University, subject name: The development and influence of Chinese copper Shang culture on copper instrument, number: TSY14009.

\section{References}

[1] Lv Hongmei. Copper Shang Culture. Chinese and foreign entrepreneurs, 2014, (9): 246-247.

[2] Wang Gui The pre Qin copper and copper Zheng Shang culture [J]. Journal of Qujing Normal University, 2015,34 (1): 48-53.

[3] Peng Shanshan. The research on the art of the bronze bell of the Qin Dynasty in Shanxi. Shanxi University, 2009.32-68. 